\section{Me gums made me do it}

\author{
S Hancocks, OBE*
}

\section{While we've all been snoozing along paying attention to media hype about amalgam, multifavoured floss and toothbrushes that sing, the world of periodontal research has moved on.}

$\mathrm{H}$ uh, yes, I know, even now you're tempted to turn away to something that you think is far 'sexier' (to use the language of today's media hype). Only a sneaking curiosity as to why I've even bothered to raise the subject is stopping you from shunning this column completely if it's going to be about gums and associatedly dreary epithelial matters. Well on your own head be it because inside information clearly says that far from implants and tooth bleaching taking charge, the new millennium will undoubtedly belong to revelations of the periodontal kind.

What am I talking about? Well, as I say, while we've all been about our business elsewhere paying scant attention to matters gin gival, the quiet perio-pink boffins in their discrete laboratories have been pocketed away. They've been looking into all sorts of fascinating tiny leads, which might just be linked with periodontology, or gum disease as we will soon realise we laughingly used to call such a significant social and pathological scourge of the twenty-first century.

There's been talk for years about connections with immunology of course. Exposures for all manner of complex sounding body juices and leuco-bits such as the well known leucocytes, the slightly more esoteric lymphokines and the positively sub-atomic inerleukins. But quite what they had got to do with brushing off a bit of plaque has been something of a mystery. Let's be frank about this, serum antibody titres, complement fixation and enhanced opsonisation have hardly had a place in the vocabulary of the average NHS practice.

Then again the researchers have had their days blessed with that ultimate in obscure scientific glamour that many strive for but few achieve, test tubes full to the brim with micro-organisms christened with names that defy articulation. Porphyromonas gingivalis and Bacteroides forsythus are hardly designations that trip easily from the tongue over a champagne cocktail. While learnedjournal layout staff the world over curse as they try and get their desktop publishing programs to compute a suitable word wrap- around or hyphenation for Actinobacillus actinomycetemcomitans.

It is not so much these complex nuts and bolts that are causing the revolution but the theories that longevity and good fortune comes to those with healthy pink support bits, while the hideous converse hardly bears thinking about. First gum pestilence was tentatively linked with some types of heart disease sufferers, then increasingly with a variety of heart problems. Pre-term, lowweight babies might also now be a result (in women at least) and any number of other

\section{'My mother had bad gums but I don't really blame her. Nobody knew the significance in those days.'}

systemic conditions and habits are now insinuated as associated risk factors; diabetes, smoking and even stress. And who amongst us doesn't fall into one of those categories? So how much longer will it be before the hemidesmosomal detectives discover a link with all sorts of hitherto unsuspected complaints stemming from deep periodontal folds? Personality defects perhaps? Genetics is as obviously involved here as in many other areas of human disease progression. What if your family history includes crestal bone depletion, furcation involvement and serious fraud?

And with all this at stake, identifying risk factors is obviously going to be the future. Gone will be the homely days in which a dental laboratory on the premises was a footfall away into a genteel world of wax encrusted benches, half-drunk cups of Nescafe and smeary old acrylic flasks. Instead, read high tech conglomerations of mega-sophisticated equipment monitoring rising and falling levels of Ig-this and

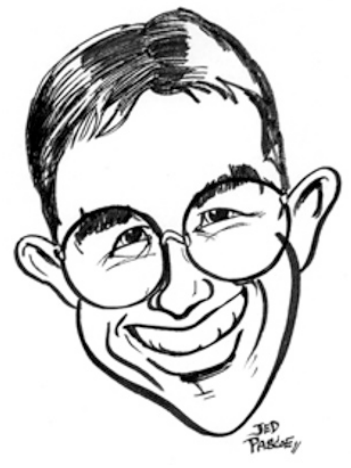

haemolysin-that. History too will be the faithful technician who's been in the business for as many years as you can remember. Instead, in comes the DNA-profiling biological equivalent of a rocket scientist to ensure that any warning signs from a newly developing three-walled defect can be instantly centrifuged, radioactively labelled and cross-matched with the global perio data bank.

Never mind Corporate Bodies, as the brave new millennium progresses any venture capitalist worth his, or her, salt will be dropping shares in internet companies like hot bricks and ploughing their cash into high street chains of periodontal screening centres.

It also seems highly likely that periodontal therapy will have a much more profound definition, involving sessions lying on a couch talking through your problem with a trained counsellor.

'What sort of relationship did you have with your parents?'

'Well, my mother had bad gums but I don't really blame her. Nobody knew the significance in those days.'

'It's OK, this is a common story. You're not alone on this one. Trust me.'

Crime movies will not let the development pass either. Anxious New York cops will suck the Manhattan night air in through clenched teeth as their officers bang another suspected felon across a car bonnet. 'Does he have a record?' snarls the lieutenant.

'Yes sir', the eager rookie replies, 'CPITN of 3 and a Löe-Silness score of 2.5.'

'Book him before he pleads the periodontal amendment.'

Courtroom scenes too will take on a whole different feel as the defence rises to plead mitigating circumstances to the jury. 'Of course he is sorry for what he did but I ask you as honest, caring citizens to consider his plaque index and pocket depths.

And, just in case you think this is all complete madness, I want you to realise that it is not my fault, 'me gums made me do it'.

* The author is commissioning editor for the BDJ 